\title{
EXPERIMENTAL RESEARCH REGARDING MAGNETIC SEPARATION OF SEEDS AFTER THEIR SURFACE CONDITIONS USING TWO MOISTENING LIQUIDS
}

\author{
Valeria Gabriela Ciobanu, Alexandra Liana Visan, Anisoara Paun, Gabriel Bogdanof \\ National Institute of Research - Development for Machines and Installations \\ Designed to Agriculture and Food Industry - INMA, Romania \\ dns.gabriela@yahoo.com
}

\begin{abstract}
One of the most dangerous and destructive parasitic weed seed is dodder, and due its impact it is registered in the list of crops risk factors and it also affects directly the animal health. At national level, the damage that it generates in agricultural crop production reaches 50-100\% and worldwide it is causing crop losses of $14-15 \%$. For this reason the forage plant production is determined by the seed purity the in sowing process, at national and international regulations it is required to be $100 \%$ free of dodder seeds, because a single dodder seed can compromise the whole culture. Complete separation of dodder seeds from the basic culture seed mass is a complex and very difficult process, due to its shape, dimensions and its aerodynamic properties, which often are very similar. An effective separation is the magnetic separation method - a process with high complexity that does not affect the basic seed material properties, in which magnetic drums and fine iron powder are used. Due to the fact that dodder seeds have rough external surface on which wrinkles and fine threads can rise, which are filled with iron powder and gain ferromagnetic properties. The magnetic drums retain the dodder seeds or modify their trajectory, drawing them to the rational drum. The basic culture seeds continue their movement to a separation zone due to their smooth outer surface. In this paper, the experimental research will be presented in view of obtaining a seed material "free" of dodder, pursuing the influence of the drum speed on the seed behavior in the process of separation, improving the degree of adhesion of iron powder to the roughened surface of dodder seeds by using two wetting liquids and reducing the number of passes of seeds through the separator.
\end{abstract}

Keywords: magnetic separation, iron powder, dodder seeds.

\section{Introduction}

The parasitic weed seeds in national [1-3] and international [4] legislation are considered quarantine plants and their presence is prohibited in seeding material mass, in fodder material and food industry. In this category more than 20 plants are named (as: Ambrosia, Euphorbia, Sorgum, Sicyos, etc.) and one of them is also dodder, Fig. 1 [5].

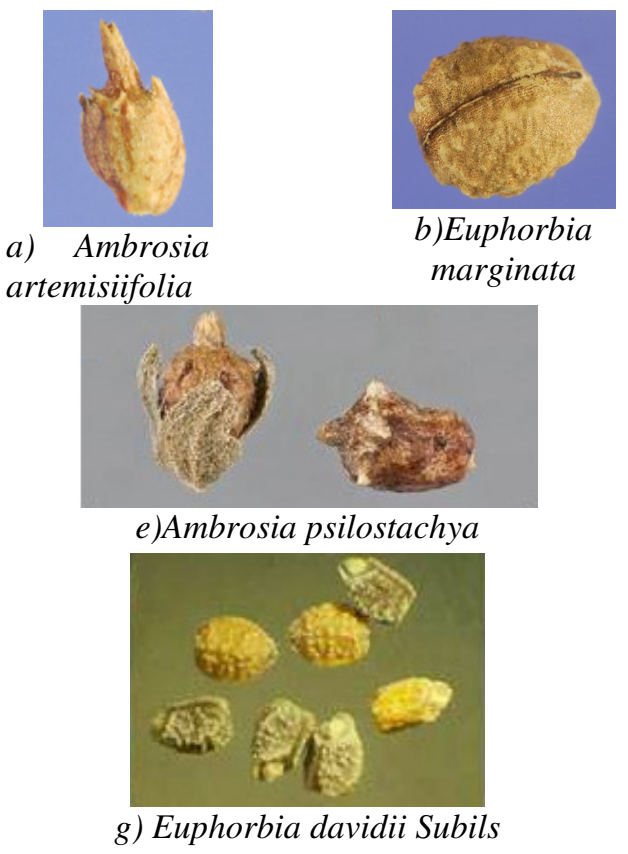

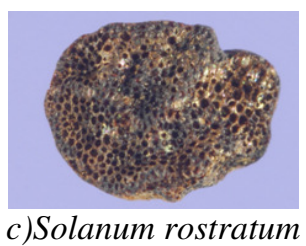

c)Solanum rostratum

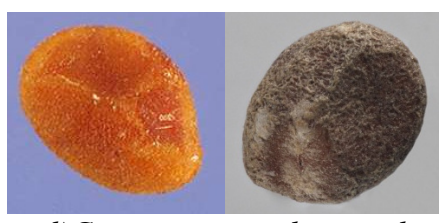

d)Cuscuta suaveolens and campestris

g) Euphorbia davidii Subils

Fig. 1. Quarantine weeds with rough surfaces [5]

The separation process of parasitic weed seeds from the basic seed material is difficult to conduct from the technical point of view, because the dedicated equipment and installations cannot be successfully used for seed separation that are manly worked according to their density (machines and 
equipment with sieves and air currents) [6-8]. Dodder seeds (known in scientific literature as Cuscuta), cannot be completely separated from the perennial fodder seeds mass, and the waste resulted, along with the dodder seeds are also other impurities (underdeveloped basic crop seeds, breaks, etc.) and the sowing material losses reach 7-27\% [7], and thus the harvesters are impaired holdings up to $100 \%$. In order to avoid this case, INMA had developed an experimental model of magnetic separation equipment in order to realize a total dodder seed separation, but this technology can be applied also for other seeds with rough external surfaces, as: Ambrosia artemisiifolia, Euphorbia marginata, Sicyos angulatus, Cenchrus longispinus, Solanum rostratum, etc., see Fig.1. [5]. This technology is provided with a dedicated sorting system designed based on the magnetic drum separation principle, inspired after the metallurgical installations, respectively form the iron ore separation equipment that was adjusted to process small-sized materials (like dodder seeds that can be compared to small granulation materials) with low magnetic induction [9-12]. Its construction consists of: a feed hopper equipped with a dosing system; a seed moistening system - to increase the outer seed coverage surface with iron powder; an iron powder dosing system; a mixing chamber; a prone screw; a conveyor, a vibrating table - to achieve an uniform seed flow; the rotary magnetic drum - magnetic separation system and also a multilevel collecting system. In Fig.2, the working principle of such magnetic drum separation machine is presented, where the yellow dots represent the quarantine weed seeds and the red dots are the sowing material.

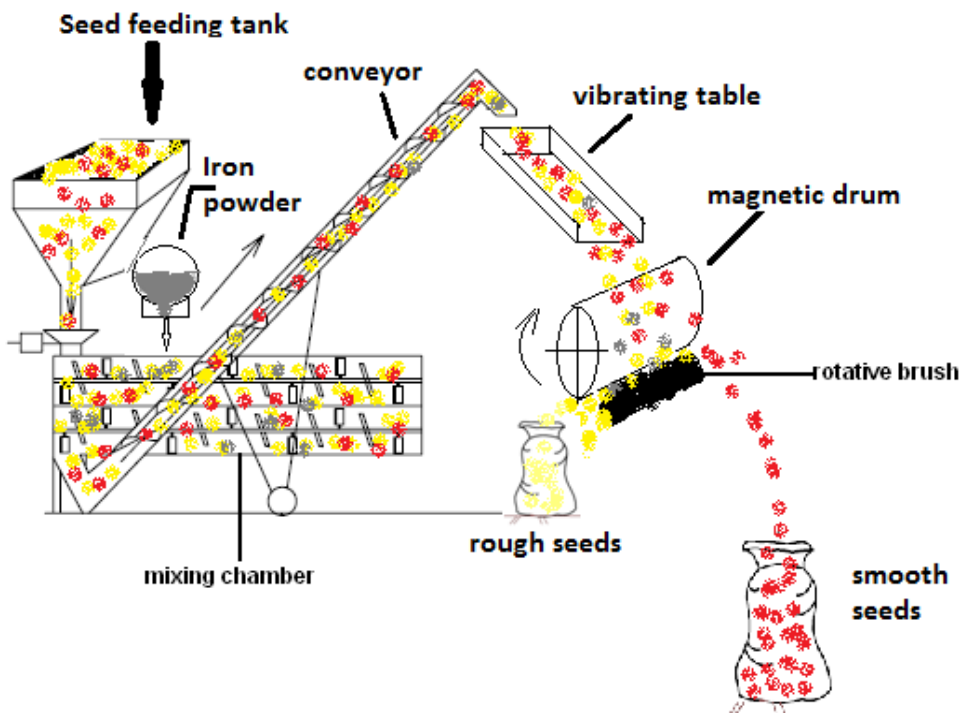

Fig. 2. Magnetic drum machine working principle [13]

The dodder covering grade with iron powder is very important because on it the magnetic inductance depends and therefore the dodder separation level. Due to this fact several research activities were conducted at INMA Bucharest to determine the factors that determine the covering grade. Taking into consideration that this activity is very demanding and the procedure is burdensome and long lasting, in this paper only an example in Fig.3 is presented. Analyzing the outer surface structure of a dodder seed using a Greenough Stereo Microscope Leica S6 E, at 16x and 20x dioptre the seed covering grade was estimated with fine iron powder in order to determine the magnetic inductivity what is directly influenced by the gained ferromagnetic properties. Manly this method is used to estimate the performance of the seed separating process - respectively, the uniformity of the mixing process that strongly influences the seed adherence on the magnetic drum surface, Fig. 3, [8; $11 ; 12 ; 14]$.
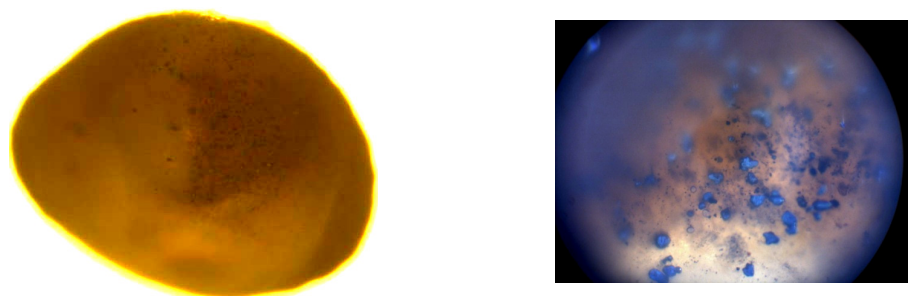

Fig. 3. Dodder seed covered with iron powder - microscope images 
Taking into consideration the fact that this equipment can be used also in forage and food industry, it is necessary to comply with the processed material safety requirements and for this reason the quantity of iron powder must be reduced so as not to deposit on the surface of basic seed. Conducting the research in the dodder seed morphology, their appearance has been found depending on the species, seeds with rough external surfaces (Cuscuta Palaestina) [15], with wrinkles (Cuscuta campestris) [5] and fine threads (Ipomoea pandurata - Fig. 3c) [5], Fig. 4.

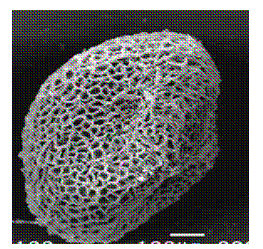

a) Cuscuta Palaestina

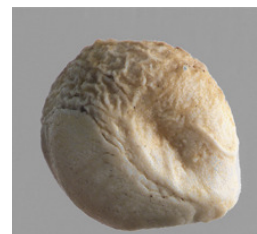

b)Cuscuta campestris

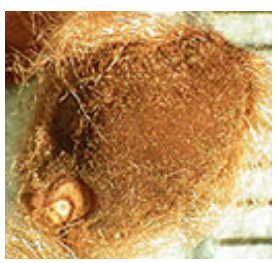

c) Ipomoea pandurata

Fig. 4. Dodder seed morphology

For this reason several experimental research activities were conducted in order to compare two dodder magnetic separation processes, the case in which the seeds are moistened only with water and the one with a solution made from water and glycerin. The last method is relatively new and patented, but in scientific literature there are not yet published results obtained by using this solution. It is therefore necessary that this method can be applied on INMA equipment and as well as to determine its performance.

\section{Materials and methods}

In the research activities were used: MD-400 magnetic separation equipment, alfalfa crop - new ferruginea Alfalfa, dodder seeds, minimum $99 \%$ fine iron powder chosen in order to adequate to the dodder outer surface, water and solution (mixture of water and glycerin). The glycerin substance is a bio substance that has the property to be hygroscopic, easily soluble, colorless, sweet, odorless and it vaporizes at the end of the process. The MD-400 magnetic separation equipment works by the technological scheme shown in Fig. 5, and there were not required any changes on the moistening system or other parts.
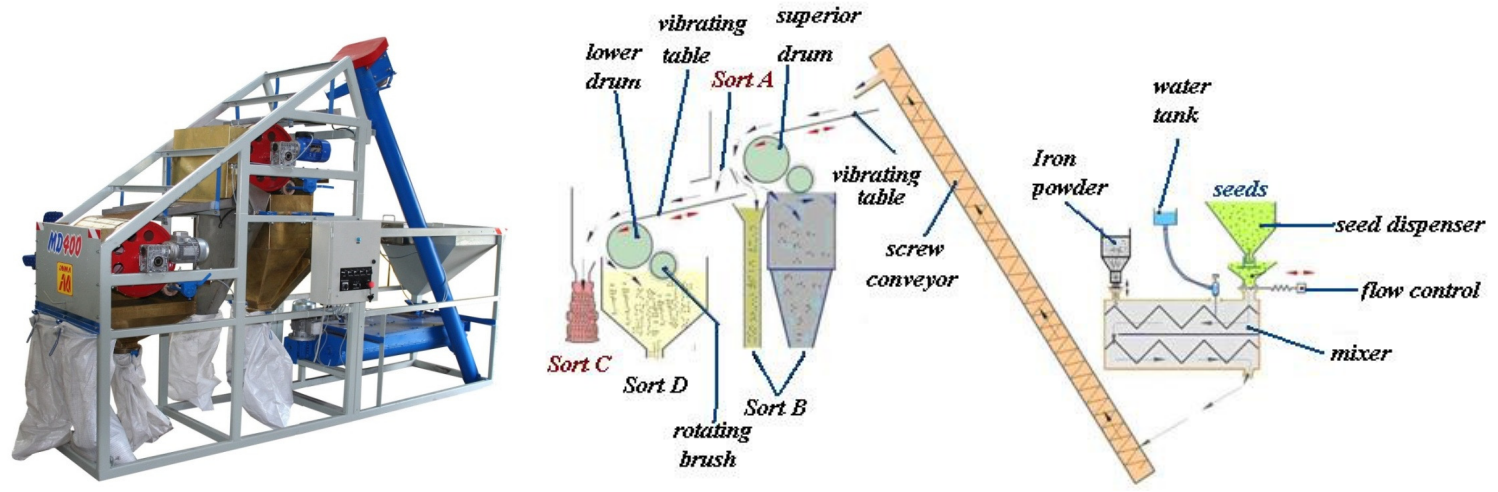

Fig. 5. Technological scheme of the MD - 400 machine [5; 14]

For each case, in the first step it is necessary to evaluate the contamination level of the supplied seeds, the grade that is established according to national regulations and according to its level the moisture grade and the iron powder flow are established. The second step is to gather samples from each collector, in which a certain seed category is gathered, Fig. 5. The sort A represents the smooth seeds (the alfalfa seeds) that pass-through the first separation operation (superior magnetic drum). The seeds collected by sort B represent a fraction of: dodder seeds, cracks and stubble covered by iron powder, these are collected by the superior drum and the other fraction is collected by the lower drum and gathered in sort D. At the end of the technologic process clean smooth seeds (alfalfa seeds) are obtained in sort C. The third step is to evaluate the quality of the output seeds and their contamination level, the level that in national and international regulation must be 0 - free of quarantine seeds. If this requirement is not achieved the seed material must pass-through MD-400 for another time. 
Appling the methodology described above the initial seed material supplied to MD-400 equipment was assessed, and the dodder seed presence in $100 \mathrm{~g}$ of seeds was 380 pieces,

The experiments were conducted in the same conditions in both cases: the magnetic drum speed is $20 \mathrm{rot} \cdot \mathrm{min}^{-1}$; the seed flow rate was maintained at the same value $25.39 \mathrm{~g} \cdot \mathrm{s}^{-1}$; the iron powder flow rate is increased 3 times $\left(10,15\right.$ and $\left.19 \mathrm{~g} \cdot \mathrm{min}^{-1}\right)$; the moistening liquid had been adjusted at 38, 30 and 22 drops $\cdot \min ^{-1}$ - in case when the glycerin solution with water was administrated. The moistening solution had a concentration of $0.71 \%$, which represents $5 \mathrm{ml}$ of glycerin at 0.71 of water.

Appling this methodology the influence of the solution flow rate on the separation process quality is pursued, and also the influence of iron powder flow rate on the number of seeds passing through the machine.

\section{Results and discussion}

The experimental results when the iron powder flow rate was maintained constant at $10 \mathrm{~g} \cdot \mathrm{min}^{-1}$ and the water flow rate was 38,30 and 22 drops $\cdot \mathrm{min}^{-1}$. The relevant results obtained by applying the experimental methodology are the number of dodder seeds present in sort A and C. In Table 1, the values for the magnetic separation process are presented when water and glycerin solution is used when the seed material passes-through the MD-400 equipment 4 times $(T)$.

\section{Dodder seed content from sort $\mathrm{A}$ and $\mathrm{C}$ for $10 \mathrm{~g} \cdot \mathrm{min}^{-1}$ iron powder}

Table 1

\begin{tabular}{|c|c|c|c|c|}
\hline \multicolumn{2}{|c|}{ Sort A } & Sort $C$ & Sort A & Sort $C$ \\
\hline \multicolumn{3}{|c|}{ Water } & \multirow{2}{*}{\multicolumn{2}{|c|}{$\frac{\text { Solution (glycerin solution) }}{38 \text { drops } \cdot \mathrm{min}^{-1}}$}} \\
\hline \multicolumn{3}{|c|}{38 drops $\cdot \mathrm{min}^{-1}$} & & \\
\hline $\mathrm{T} 1$ & 108 & 72 & 64 & 30 \\
\hline $\mathrm{T} 2$ & 44 & 30 & 12 & 4 \\
\hline T3 & 18 & 4 & 2 & 0 \\
\hline $\mathrm{T} 4$ & 2 & 0 & & \\
\hline \multicolumn{3}{|c|}{38 drops $^{\prime} \mathrm{min}^{-1}$} & \multicolumn{2}{|c|}{$30 \mathrm{drops}^{\prime} \mathrm{min}^{-1}$} \\
\hline $\mathrm{T} 1$ & 108 & 72 & 80 & 42 \\
\hline $\mathrm{T} 2$ & 44 & 30 & 28 & 8 \\
\hline T3 & 18 & 4 & 4 & 0 \\
\hline $\mathrm{T} 4$ & 2 & 0 & & \\
\hline \multicolumn{3}{|c|}{38 drops $\cdot \min ^{-1}$} & \multicolumn{2}{|c|}{22 drops $\cdot \min ^{-1}$} \\
\hline $\mathrm{T} 1$ & 108 & 72 & 96 & 54 \\
\hline $\mathrm{T} 2$ & 44 & 30 & 36 & 18 \\
\hline T3 & 18 & 4 & 10 & 4 \\
\hline $\mathrm{T} 4$ & 2 & 0 & 0 & 0 \\
\hline
\end{tabular}

The values presented above represent that if the liquid flow rate (respectively $38 \mathrm{drops} \cdot \mathrm{min}^{-1}$ ) is applied, the quality requirements (free of dodder seed) are reached with less passes if glycerin solution is used. When the glycerin solution flow rate is higher than 30 drops $\cdot \mathrm{min}^{-1}$ the seed quality from sort A is higher and the second separation can lead to meet the quality requirement. Using the same quantity of iron powder it was found that to obtain a minimum content of dodder seeds in sort $\mathrm{C}$ it is recommended to use the glycerin solution.

Increasing the iron powder flow rate to $15 \mathrm{~g} \cdot \mathrm{min}^{-1}$, the results presented in Table 2 were obtained.

If the iron powder flow rate was increased and the glycerin solution flow rate was $38 \mathrm{drops} \cdot \mathrm{min}^{-1}$ the quality conditions were achieved at the second pass of the material, the values that can be achieved at the third pass if only water is used. If the solution flow rate is decreased the free dodder seed quality state can be reached from only 3 passes, the fact that leads to energy saving and shorter processing time.

In Table 3 the results regarding the dodder seed content in Sort A and C are presented when the iron powder flow rate is increased to $19 \mathrm{~g} \cdot \mathrm{min}^{-1}$. 
Dodder seed content from sort $A$ and $C$ for $15 \mathrm{~g} \cdot \mathrm{min}^{-1}$ iron powder

Table 2

\begin{tabular}{|c|c|c|c|c|}
\hline \multicolumn{2}{|c|}{ Sort A } & Sort $C$ & Sort A & Sort $C$ \\
\hline \multicolumn{3}{|c|}{ Water } & \multicolumn{2}{|c|}{ Solution (glycerin solution) } \\
\hline \multicolumn{3}{|c|}{38 drops $\cdot \min ^{-1}$} & \multicolumn{2}{|c|}{38 drops $\cdot$ min $^{-1}$} \\
\hline $\mathrm{T} 1$ & 86 & 42 & 42 & 18 \\
\hline $\mathrm{T} 2$ & 36 & 18 & 6 & 0 \\
\hline T3 & 6 & $0(2)$ & & \\
\hline \multicolumn{3}{|c|}{38 drops $\cdot \min ^{-1}$} & \multicolumn{2}{|c|}{30 drops $\cdot \min ^{-1}$} \\
\hline T1 & 86 & 42 & 54 & 26 \\
\hline $\mathrm{T} 2$ & 36 & 18 & 20 & 6 \\
\hline T3 & 6 & $0(2)$ & 10 & 0 \\
\hline \multicolumn{3}{|c|}{38 drops $^{\prime} \min ^{-1}$} & \multicolumn{2}{|c|}{22 drops $\cdot \mathrm{min}^{-1}$} \\
\hline T1 & 86 & 42 & 68 & 38 \\
\hline T2 & 36 & 18 & 30 & 14 \\
\hline T3 & 6 & $0(2)$ & 4 & 0 \\
\hline
\end{tabular}

Table 3

Dodder seed content from sort $\mathrm{A}$ and $\mathrm{C}$ for $19 \mathrm{~g} \cdot \mathrm{min}^{-1}$ iron powder

\begin{tabular}{|c|c|c|c|c|}
\hline \multicolumn{2}{|c|}{ Sort A } & Sort $C$ & Sort A & Sort C \\
\hline \multicolumn{3}{|c|}{ Water } & \multicolumn{2}{|c|}{ Solution (glycerin solution) } \\
\hline \multicolumn{3}{|c|}{$38 \mathrm{drops} \cdot \mathrm{min}^{-1}$} & \multicolumn{2}{|c|}{$38 \mathrm{drops} \cdot \mathrm{min}^{-1}$} \\
\hline $\mathrm{T} 1$ & 44 & 26 & 4 & 0 \\
\hline $\mathrm{T} 2$ & 18 & 6 & \multirow{2}{*}{\multicolumn{2}{|c|}{ - }} \\
\hline T3 & 4 & 0 & & \\
\hline \multicolumn{3}{|c|}{38 drops $^{\prime} \mathrm{min}^{-1}$} & \multicolumn{2}{|c|}{$30 \mathrm{drops} \cdot \mathrm{min}^{-1}$} \\
\hline T1 & 44 & 26 & 12 & 4 \\
\hline $\mathrm{T} 2$ & 18 & 6 & 2 & 0 \\
\hline T3 & 4 & 0 & & \\
\hline \multicolumn{3}{|c|}{38 drops $\cdot$ min $^{-1}$} & \multicolumn{2}{|c|}{22 drops $\cdot \mathrm{min}^{-1}$} \\
\hline $\mathrm{T} 1$ & 44 & 26 & 24 & 8 \\
\hline $\mathrm{T} 2$ & 18 & 6 & 4 & 2 \\
\hline T3 & 4 & 0 & 0 & 0 \\
\hline
\end{tabular}

In this case, the separation process is considerably reduced and the "free" dodder seed quality requirement is reached only by 1 pass through the MD-400 equipment, when the glycerin solution flow rate is 38 drops $\min ^{-1}$, but it requires a higher quantity of iron powder to carry out the total separation.

\section{Conclusions}

Following the comparative analysis of dodder magnetic separation by these two methods, with water and glycerin moistening liquids, it can be concluded that:

1. The numeric dodder seeds content in sort $\mathrm{A}$ and $\mathrm{C}$ is considerably reduced if glycerin solution is used at the same iron powder flow;

2. At the same quantity of powder used in these two magnetic separation processes, successfully a smaller moistening liquid amount and less base material passes can be used;

3. The dodder separation grade obtained using glycerin solution is superior regarding the classic method - water, and the separating process can be made also by one rotary magnetic drum using less moistening liquids;

4. Choosing the correct dosage of the moistening liquids/solutions and iron powder a "free" of dodder seed material can be obtained by only one pass through the machine;

5. The MD-400 equipment is adequate also for usage of the glycerin solution and the separation process is shorter and more performant. 
6. The expanses in magnetic separation can be considerably lower because: the power costs are lower - less passes; less iron power consumption; lower moisture and fewer losses.

\section{Acknowledgement}

This work was funded by Romanian National Authority for Scientific Research and Innovation (ANCSI), on NUCLEU Program, PN 16240301 „Innovative technology and equipment for superior valorization of soybeans seed in animal feed, PN 16240304 "Innovative technology and technical equipment for the superior capitalization of cereals by flattening for use in animal feed".

\section{References}

1. Decree no. $155 / 29.06 .2010$, production of seeds for marketing fodder plant.

2. Decree no. 253/2011, regarding certain marketing derogations of fodder mixtures plant seeds used to protect the natural environment in Romania.

3. Decree no. 1521/2013 that modifies the Minister of Agriculture and Rural Development Order no. 155/2010 regarding the selling of fodder plant seeds for production and marketing.

4. International Seed Testing Association, Rules Proposals for the International Rules for Seed Testing 2015 Edition, Chapter III Purity Annalise, pp. 9-11, [online][17.12.2016] Available at: https://www.seedtest.org/upload/cms/user/OGM1405ProposedChangestotheISTARulesfor2015.pdf.

5. Ciobanu V.G., Vişan Alexandra Liana, Constientizarea necesităţii controlului integrat al buruienilor parazite in culturile agricole, (Raising awareness of the parasitic weeds integrated control need in agricultural crops), published by INMA Bucharest - electronic format course, [online][17.12.2016] Available at: http://www.envirobg.eu/

6. Letoşnev M.N., Maşini Agricole (Agricultural Machines) Ministry of Agriculture and Forestry. Publisher Agro-Forestry state, Bucharest 1959.

7. Hălălău D., Păun M., Şarpe N., Cuscutele din România şi combaterea lor (Dodders in Romania and their combat). Ceres Publish House, Bucharest, 1980.

8. Tănase M., Oprean L., Barbu C.H., Chemical control of dodder (Cuscuta L.) in alfalfa cultures. INNOVACIO., A tudomany es a gyakorlat egysege az ezredfordulo agrariumaban novenytermesztes, 2002, pp. 389-397.

9. Edward D., Holtham P.N., Kojovic T., The motion of mineral sand particles on the roll in high tension separators. Magnetic and Electrical Separation 1994, vol. 6, pp. 69-85.

10. Molteni D., Magnetic separator with ferrite and rare earth permanent magnets, Patent no. 7,564,333 B2, Jul. 21, 2009.

11. Căsăndroiu T., Ciobanu V., Păun A., Mathematical models for describing the seeds motion in separation processes, 43-rd International Symposium "Actual Tasks on Agricultural Engineering" 2015, pp. 405-416.

12. Căsăndroiu T., Ciobanu V., Moise V., Vişan A.L., Theoretic aspects of seed motion on drum surface of electromagnetic separation machines. Applied Mechanics and Materials 2014, vol. 656, pp. 305-314.

13. Căsăndroiu T., Ciobanu V. G., Visan A., Numerical simulation of the movement of smooth particles at the electromagnetic separators with drum, The 11th International Conference „Constructive and Technological Design Optimization in the Machines Building Field" OPROTEH. A. Optimization of manufacturing processes and systems \& computer aided design and manufacturing (CAD, CAM, CAE, CAPP) / A1. Bacau. 2015.

14. Ciobanu V., Căsăndroiu T., Ciupercă R., Păun A., Researches on seeds mixture mechanical separation systems according to their surface, Renewable Energy and Rural Development TE-RERD, 20-22 June 2013, pp. 133-138.

15. Khalik K.N.A. Seed morphology of Cuscuta L. (Convolvulaceae) in Egypt and its systematic significance, Feddes Repertorium 117 form 2006, no. 3-4, pp. 217-224. 